\title{
Flexure of pultruded glass- fibre-reinforced polymer beams with bonded splice joints
}

\author{
Geoffrey John Turvey BSc, MSc, DIC, PhD, CEng, MICE, \\ MIStructE \\ Senior Lecturer, Engineering Department, Lancaster University, Lancaster, UK
}

Elastic moduli of pultruded glass-fibre-reinforced polymer beam and plate profiles are presented. The method used to fabricate three beams, each with a six-plate bonded splice joint at mid-span, is outlined. Details of the instrumentation used to measure deflections, etc. during three-point flexure tests on the beams are given. Deflections, support rotations and mid-span strains recorded during the tests are presented. Formulae, based on shear deformation beam theory, are presented for predicting the centre deflection and the support rotations of the beams. It is shown that they predict deflections and rotations with a maximum error of about $10 \%$, provided the elastic moduli are derived from coupon tests rather than the manufacturer's minimum values. The theory is extended to provide a simple method, based on the solution of a quadratic equation, for determining the optimum and limiting splice length ratios for particular values of the additional cross-sectional area and additional second moment of area factors and the shear flexibility parameter. Finally, the theory is used in three parameter studies to assess the effects of splice length ratio, adhesive thickness and modulus, splice plate thickness and splice joint layout on the normalised mid-span deflections of spliced beams.

\section{Introduction}

Since the early 1990s interest in the use of pultruded glass-fibrereinforced polymer (GFRP) profiles in infrastructure has continued to grow. At the same time, research into the structural behaviour of the profiles has also increased, so much so that there is now a good understanding of the bending and local/lateral buckling behaviour of GFRP beam profiles, especially I and wide flange (WF) sections. Likewise, there is a similar level of understanding of the behaviour of WF section columns. Nevertheless, there are a number of facets of the behaviour of pultruded GFRP structures where research is needed. In particular, the behaviour of joints, both bolted and bonded, merits significant further investigation, not least because of the wide variety of layouts used in practice.

A significant quantity of test data on bolted tension joints and semi-rigid beam-to-column joints between pultruded GFRP profiles has been reported in Europe and North America since the early 1990s. Several summaries of the principal joint test series completed up to about 2004 have been compiled (Mottram and Turvey, 2003; Turvey, 2000; Turvey and Cooper, 2004). However, the behaviour of bonded joints between pultruded GFRP profiles has not been investigated to the same extent. Even so, useful contributions to understanding the behaviour of bonded tension joints between pultruded GFRP profiles have been reported
(Keller and Vallée, 2005a, 2005b; Vallée et al., 2006a, 2006b; Zhang and Keller, 2008). There is, of course, a wealth of tension test data on bonded joints in the aerospace literature, but it has mostly involved carbon fibre reinforced polymer (CFRP) laminates made by processes other than pultrusion. Moreover, because the fibre types (carbon rather than glass), fibre architectures (unidirectional laminae with various orientations rather than rovings (unidirectional fibre bundles) and continuous filament mat (CFM)) and the thicknesses (up to $2-3 \mathrm{~mm}$ for aerospace and greater than $3 \mathrm{~mm}$ for infrastructure) differ, aerospace bonded joint test data are generally not directly applicable to bonded joints between pultruded GFRP profiles.

The behaviour of bonded pultruded GFRP joints in bending rather than tension appears not to have been investigated. These joints arise in practice when it is necessary to connect beam profiles end-to-end to increase their spans or when a damaged section has to be repaired. Such joints are referred to as splice joints in steel construction. Indeed, riveted and bolted splice joints have been used for more than a century and welded splice joints for many decades.

Recognition of the lack of information on the behaviour of bonded splice joints in flexure provided the catalyst for the present paper on the analysis and testing of the flexural response 
of pultruded GFRP WF beams with bonded splice joints at midspan. Details are given of the elastic properties of the pultruded GFRP WF beam and GFRP plate profiles used to fabricate beams with central splice joints. This is followed by a detailed description of the steps involved in the fabrication of three beams with splice joints of different lengths for testing up to the deflection serviceability limit. The beam test setup, instrumentation and test procedure are then outlined and test results for loading in threepoint flexure are presented. A simple analysis to predict the load-deformation response of the spliced beams is briefly outlined and closed-form expressions are given for the mid-span deflection and support rotations. A comparison of the theoretical and experimental deflections and rotations is presented. The analysis is then extended to show how the optimum and limiting splice lengths may be identified. Finally, the results of several parameter studies are presented that show how changing the elastic properties of the adhesive and splice plates and changing the layout of the splice joints affect the mid-span deflections of spliced beams.

\section{Pultruded GFRP beam and splice plate details}

The pultruded GFRP beams were WF profiles with nominal cross-section dimensions of $152 \times 152 \times 6.4 \mathrm{~mm}$ and the splice plates were nominally $6.4 \mathrm{~mm}$ thick. Both the beams and the splice plates were Extren 500 series material (reference to any trade names in this paper is solely for the purposes of factual accuracy; no endorsement of the product is implied). The Eglass-fibre reinforcement in the beam and plate profiles is in two forms - rovings and CFM. The rovings in the plate are nominally uniformly spaced across its width, whereas in the flanges and web of the beams they are packed side by side. Consequently, the longitudinal stiffness (parallel to the rovings) of a plate profile is lower than that of a beam profile. The function of the CFM is to provide the profiles' transverse stiffness and strength. The matrix material of the Extren 500 series profiles is a mixture of isophthalic polyester resin and clay/chalk filler. Typical volume percentages of glass fibre, polyester resin and filler used in these profiles are $30-50 \%, 40-50 \%$ and $5-10 \%$ respectively.

The longitudinal elastic and shear moduli of the beam and plate profiles are particularly relevant to the present investigation. Minimum modulus values are given in the manufacturer's design handbook (Strongwell, 1989). However, these values may be significantly smaller (up to $20 \%$ ) than moduli derived from tests on coupons cut out of the flanges and web of a beam profile and a plate profile. The moduli values are compared in Table 1.

Three pultruded GFRP beams each of length $3.1 \mathrm{~m}$ were cut out of three stocked lengths of $152 \times 152 \times 6.4 \mathrm{~mm}$ WF profile, so that they could be tested with the same span of $3 \mathrm{~m}$. The rectangular splice plates were cut out of a $2438 \times 1219 \times$ $6.4 \mathrm{~mm}$ (nominal dimensions) pultruded GFRP board, with their longer sides parallel to the rovings. The splice plates were cut to

\begin{tabular}{lcc}
\hline Type of profile & $\begin{array}{c}\text { Longitudinal } \\
\text { elastic modulus: } \\
\mathrm{kN} / \mathrm{mm}^{2}\end{array}$ & $\begin{array}{c}\text { Shear } \\
\text { modulus: } \\
\mathrm{kN} / \mathrm{mm}^{2}\end{array}$ \\
\hline Beam $(152 \times 152 \times 6.4 \mathrm{~mm})$ & 17.2 & 2.93 \\
Plate $(6.4 \mathrm{~mm}$ thick $)$ & 21.1 & $3.5-4.0$ \\
& 12.4 & 2.93 \\
& 15.2 & $3.5-4.0$
\end{tabular}

Table 1. Longitudinal elastic and shear moduli of pultruded GFRP beam and plate profiles. The upper figures in each row are the minimum values given by the manufacturer (Strongwell, 1989) and the lower ones are average values derived from several coupon tests

three lengths $(210 \mathrm{~mm}, 410 \mathrm{~mm}$ and $610 \mathrm{~mm})$ and two widths (152 $\mathrm{mm}$ and $68 \mathrm{~mm})$.

\section{Details of splice joints and fabrication procedure}

It was decided to use six-plate bonded splice joints to connect the cut ends of each beam. Therefore, each splice joint comprised two $152 \mathrm{~mm}$ wide plates bonded to the outer surfaces of the flanges and four $68 \mathrm{~mm}$ wide plates bonded to the inner surfaces of the flanges. The lengths of the plates varied according to whether the splice joint was 210,410 or $610 \mathrm{~mm}$ long. Within the joint there was a $10 \mathrm{~mm}$ gap between the beam ends. A crosssection through a splice joint is shown in Figure 1.

Several operations were involved in the fabrication of the bonded splice joints. First, each $3.1 \mathrm{~m}$ long WF beam was cut in half using a band saw. The outer surfaces of the top and bottom flanges at one end of each half-beam were then abraded to remove the surface veil over a length slightly greater than the

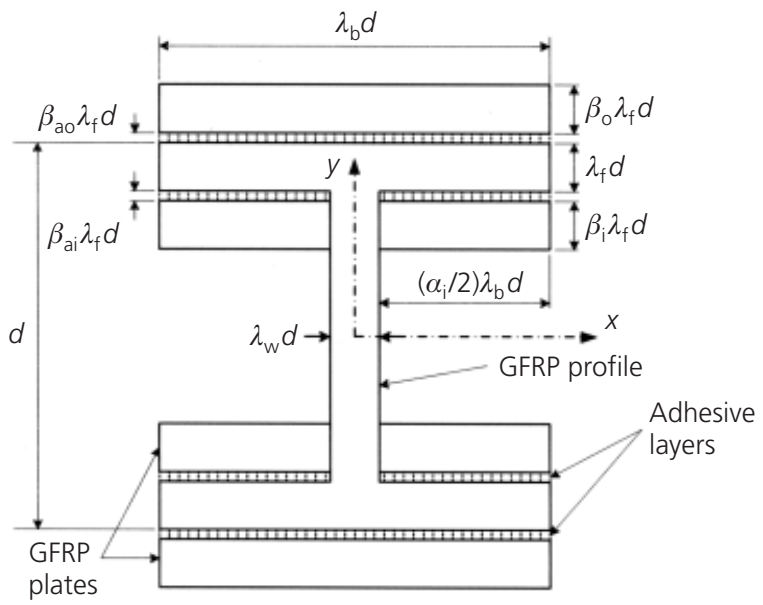

Figure 1. Cross-section through a six-plate bonded splice joint connecting the two halves of a WF profile (actual dimensions not shown) 
half-length of the splice joint. After removal of the veil and cleaning of the abraded surface, plastic tape was applied to the cut ends of the flanges and along their edges for a distance slightly longer than the half-length of the splice joint. Plastic tape was also placed across the outer faces of flanges to define the ends of the bond areas. One face of each of the outer splice plates was abraded to remove the surface veil, and plastic tape was applied along each edge. The function of the plastic tape was not only to define the bond areas but also to facilitate subsequent removal of excess adhesive. The beams were then placed lengthwise on their flange edges on two trestle tables with a gap between them sufficient to allow unfettered access to the bond areas of the joint. Araldite 2015 (a two-part epoxy adhesive) was used as the bonding medium. It was spread over the bond areas of the flanges and the splice plates. Wire spacers (approximately $1 \mathrm{~mm}$ in diameter) were placed in the adhesive to ensure, as far as possible, bond lines of uniform thickness. The alignment of the two halves of the beam was checked to ensure that the gap between their ends was $10 \mathrm{~mm}$. Thereafter, the outer splice plates were brought into contact with the flanges, checked for correct positioning and then clamped to the flanges. After curing for about $1 \mathrm{~h}$ the joint was checked and excess adhesive removed. It was then allowed to continue curing for a total of $24 \mathrm{~h}$, after which the clamps were removed. A similar procedure was then followed to bond the narrower splice plates to the inner surfaces of the flanges to complete the splice joint.

\section{Test setup, instrumentation and test procedure}

The three pultruded GFRP beams, which were simply supported at their ends $\mathrm{A}$ and $\mathrm{B}$, had spans $L=3 \mathrm{~m}$ and were loaded by a vertical point load $W$ applied at mid-span. The splice joint, of length $\lambda L$, is between $\mathrm{D}$ and $\mathrm{E}$, as shown in Figure $2 ; \lambda$ is the ratio of the length of the splice joint to the beam's span.

Instrumentation was provided to record the mid-span deflection $\delta_{\mathrm{c}}^{\mathrm{S}}$, support rotations (only $\theta_{\mathrm{B}}$ shown) and surface strains. A dial gauge with a $50 \mathrm{~mm}$ travel and a displacement resolution of $0.01 \mathrm{~mm}$ was used to measure the deflection. Electronic clinometers fixed at the mid-depth of the web vertically above each support were used to record the beam end rotations. The clinometers had an angular range of $60^{\circ}$ and a resolution of $0 \cdot 001^{\circ}$ over the initial $5-10 \%$ of the range. Two uniaxial strain

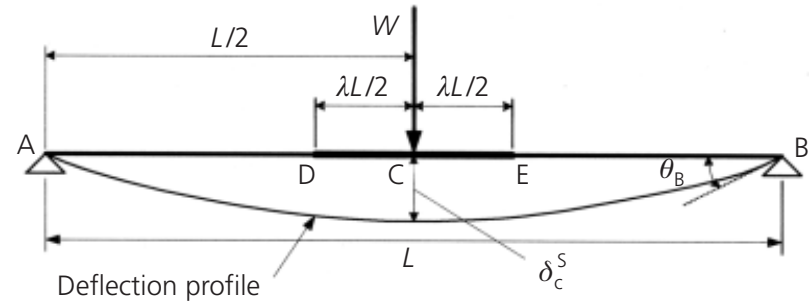

Figure 2. Simply supported three-point bending test arrangement for a pultruded GFRP beam with a bonded splice joint at mid-span gauges with their sensitive axes parallel to the beam axis were bonded to the outer surface of each outer splice plate at mid-span and inset about $10 \mathrm{~mm}$ from their edges. Their gauge lengths were $10 \mathrm{~mm}$ and their resistances were $120 \Omega$.

Because the spliced beams were only to be loaded up to the deflection serviceability limit, the test procedure was simple and straightforward. Each beam was loaded statically under displacement control by increasing the mid-span deflection in $1 \mathrm{~mm}$ increments up to a maximum value of $15 \mathrm{~mm}$ (i.e. slightly greater than the serviceability limit given by Clarke (1996)) and then unloaded to zero in $2 \mathrm{~mm}$ decrements. This procedure was repeated three times for each beam. Immediately after the application of each displacement increment/decrement, the total mid-span deflection was noted and the load, support rotations and mid-span surface strains were recorded with a hand-held data logger. Each splice beam was tested in three-point flexure with respect to both its major and minor cross-section axes.

\section{Test results}

Before presenting the main results of the experimental investigation, it is of interest to illustrate the degree of linearity and repeatability of the deflections, rotations and strains recorded during the spliced beam tests. Figure 3 shows the load-centre deflection responses of the three load tests on the beam with a $610 \mathrm{~mm}$ long six-plate splice joint at its centre. Their linearity and repeatability are excellent. Load plotted against the average value of the two support rotations obtained from the same three beam tests is shown in Figure 4. The linearity and repeatability of the average support rotations is very good. Figure 5 shows the load versus strain responses obtained from the tests on the beam with a $610 \mathrm{~mm}$ splice joint. Again, the responses are linear with good repeatability. Similar response linearity and repeatability was obtained for the beams with 210 and $410 \mathrm{~mm}$ splice joints at their centres.

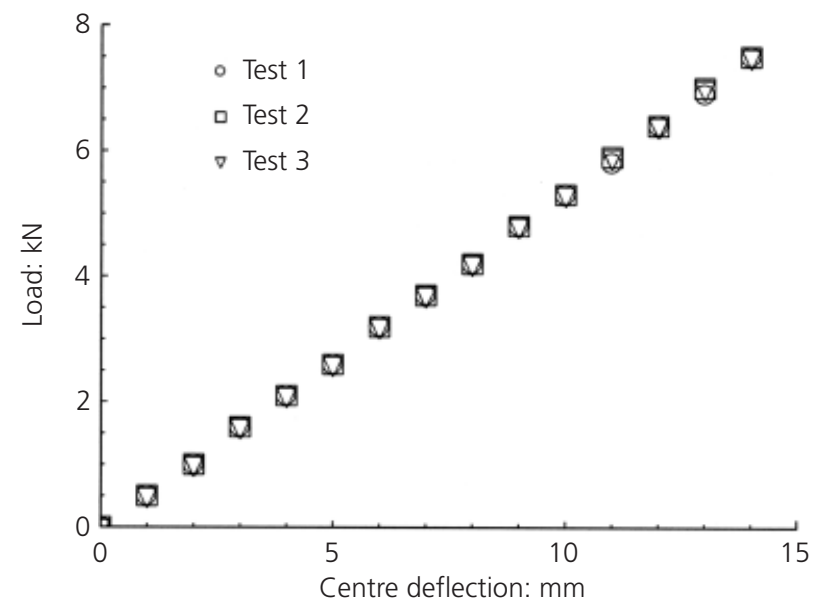

Figure 3. Load versus centre deflection response of a pultruded GFRP spliced beam $(\lambda=0 \cdot 2033, L=3 \mathrm{~m})$ 


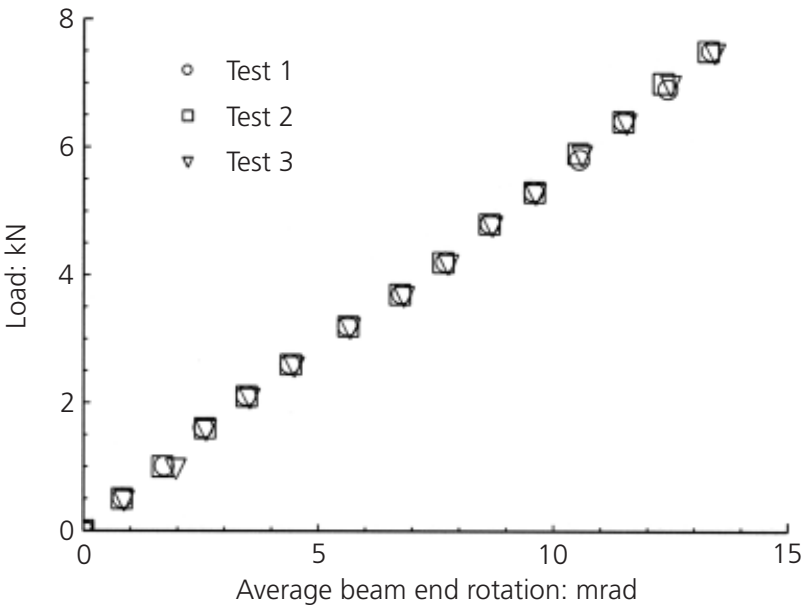

Figure 4. Load versus average support rotation response of a pultruded GFRP spliced beam $(\lambda=0.2033, L=3 \mathrm{~m})$

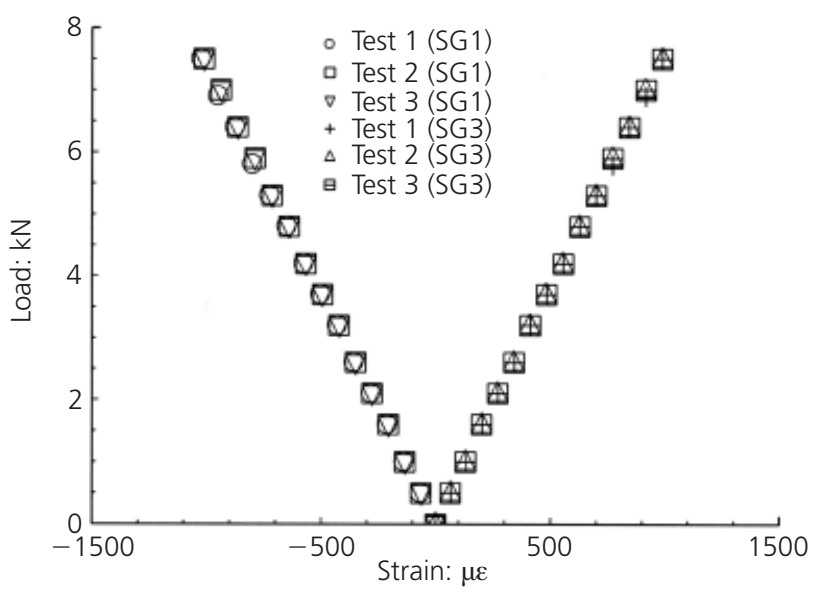

Figure 5. Load versus mid-span surface strain response of a pultruded GFRP spliced beam $(\lambda=0 \cdot 2033, L=3 \mathrm{~m})$

Figure 6 compares the load-deflection responses of all three spliced beams with the theoretical response of an unspliced beam (calculated using both the tension coupon and the manufacturer's elastic moduli (Strongwell, 1989)). The transverse stiffnesses (defined as the load per unit deflection) of the spliced beams are greater than the theoretical unspliced beam stiffnesses. However, the stiffness of the unspliced beam based on the tension coupon modulus is only slightly less than that of the beam with a $210 \mathrm{~mm}$ splice joint. Furthermore, increasing the splice length from 210 to $410 \mathrm{~mm}$ produces a greater increase in transverse stiffness than when the length is increased from 410 to $610 \mathrm{~mm}$. A similar load-deflection comparison for minor-axis flexure is shown in Figure 7. It is evident that the linearity of the response is not quite as good as that for major-axis flexure. Nevertheless, the transverse stiffnesses of the spliced beams are greater than those of the unspliced beam. Moreover, it appears that the increase in transverse stiffness with increase in splice length is smaller between splice lengths of 210 and $410 \mathrm{~mm}$ than between

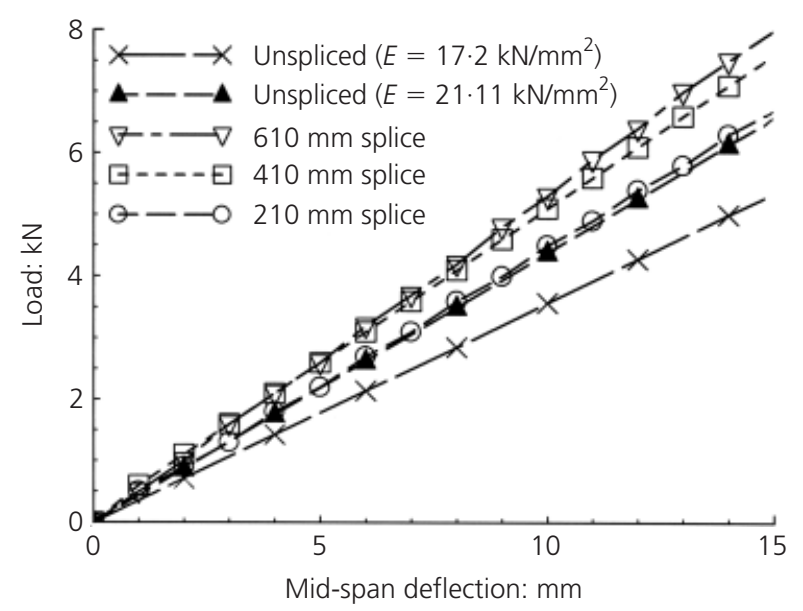

Figure 6. Comparison of the effect of splice joint length on the major-axis load versus mid-span deflection responses of spliced (test 3 data) and unspliced (theoretical) pultruded GFRP beams

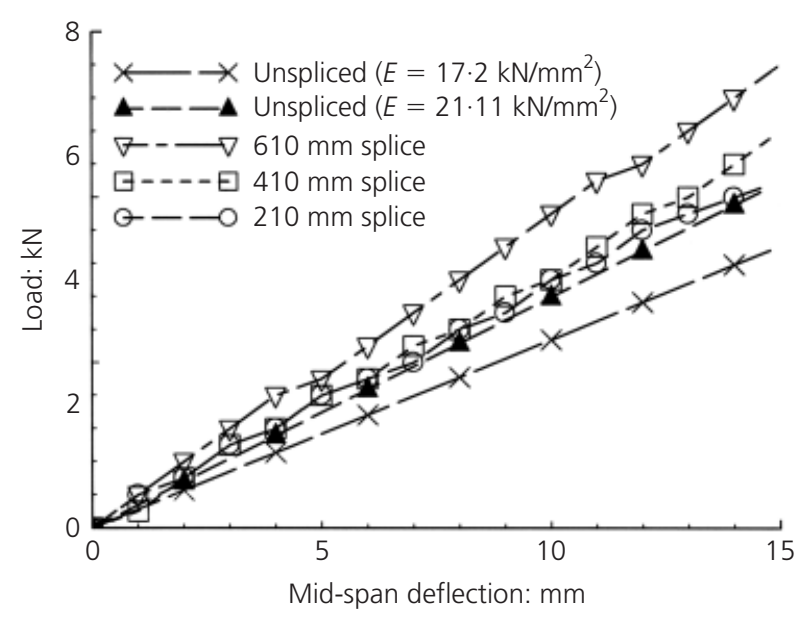

Figure 7. Comparison of the effect of splice joint length on the minor-axis load versus mid-span deflection responses of spliced (test 3 data) and unspliced (theoretical) pultruded GFRP beams

410 and $610 \mathrm{~mm}$. This is the opposite of what was observed when the beams were tested in major-axis flexure.

The transverse stiffnesses of the spliced beams were determined from the slopes of straight lines fitted to the load-deflection data in Figures 6 and 7. These stiffnesses are given in Table 2 together with the theoretical transverse stiffnesses of the unspliced beams.

\section{Spliced beam analysis}

Turvey (2008) presented a simple analysis for predicting the tip deflection and rotation of a tip-loaded CFRP stiffened GFRP cantilever beam. The analysis included flexural and shear deformation effects. Because of the analogy between tip-loaded cantilevers and simply supported beams in three-point flexure (the latter may be considered as a pair of back-to-back canti- 


\begin{tabular}{lcc}
\hline Splice length, $\lambda L: \mathrm{mm}$ & \multicolumn{2}{c}{ Transverse stiffness, $W / \delta_{c}^{S}: \mathrm{kN} / \mathrm{mm}$} \\
\cline { 2 - 3 } & Major axis & Minor axis \\
\hline 210 & 0.442 & 0.141 \\
410 & 0.503 & 0.157 \\
610 & 0.537 & 0.186 \\
$0\left(E=17.2 \mathrm{kN} / \mathrm{mm}^{2}\right)$ & 0.357 & 0.114 \\
$0\left(E=21.11 \mathrm{kN} / \mathrm{mm}^{2}\right)$ & 0.438 & 0.140
\end{tabular}

Table 2. Experimental and theoretical transverse stiffnesses of pultruded GFRP beams with six-plate bonded splice joints at midspan in major and minor-axis flexure

levers), the same equations may be used to predict the mid-span deflection and support rotations of pultruded GFRP beams with bonded splice joints at mid-span. Using the notation given in Figure 2, the equation for the spliced beam's mid-span deflection $\delta_{\mathrm{c}}^{\mathrm{S}}$ may be expressed as:

$$
\begin{aligned}
\delta_{\mathrm{c}}^{\mathrm{S}}= & \frac{W L^{3}}{48 E I}\left[(1-\lambda)^{3}+\frac{\lambda\left(3-3 \lambda+\lambda^{2}\right)}{\left(1+\phi_{\mathrm{I}}\right)}\right. \\
& \left.+12 \alpha\left\{(1-\lambda)+\frac{\lambda}{\left(1+\phi_{\mathrm{A}}\right)}\right\}\right]
\end{aligned}
$$

and the equation for the end rotations is

2.

$$
\left|\theta_{\mathrm{A}}\right|=\left|\theta_{\mathrm{B}}\right|=\frac{W L^{2}}{16 E I}\left[(1-\lambda)^{2}+\frac{\lambda(2-\lambda)}{\left(1+\phi_{\mathrm{I}}\right)}\right]
$$

where $E$ is the longitudinal elastic modulus of the beam, $I$ is its second moment of area with respect to either its major or minoraxis and $\alpha\left(=E I / G A L^{2}\right)$ is a shear flexibility parameter in which $A$ is the cross-sectional area and $G$ is the shear modulus of the unspliced beam.

Terms $\phi_{\mathrm{A}}$ and $\phi_{\mathrm{I}}$ are factors that define the increases in crosssectional area and second moment of area, respectively, due to the bonded splice plates. The method of transformed sections (Case and Chilver, 1959) was used to derive equations for these factors. For major-axis bending, a cross-section through the splice joint is shown in Figure 1. The corresponding transformed crosssection is shown in Figure 8. The transformed cross-section dimensions are defined in terms of the depth $d$ of the unspliced beam cross-section. Thus, $\lambda_{\mathrm{b}}, \lambda_{\mathrm{f}}$ and $\lambda_{\mathrm{w}}$ are the ratios of the flange width, flange thickness and web thickness to the beam depth, respectively, $\beta_{\mathrm{o}}, \beta_{\mathrm{i}}, \beta_{\mathrm{ao}}$ and $\beta_{\mathrm{ai}}$ are the ratios of the outer and inner splice plate thicknesses and the outer and inner adhesive thicknesses to the flange thickness, respectively, $\alpha_{\mathrm{i}}$ is the ratio of the total inner splice plate width to the flange width,

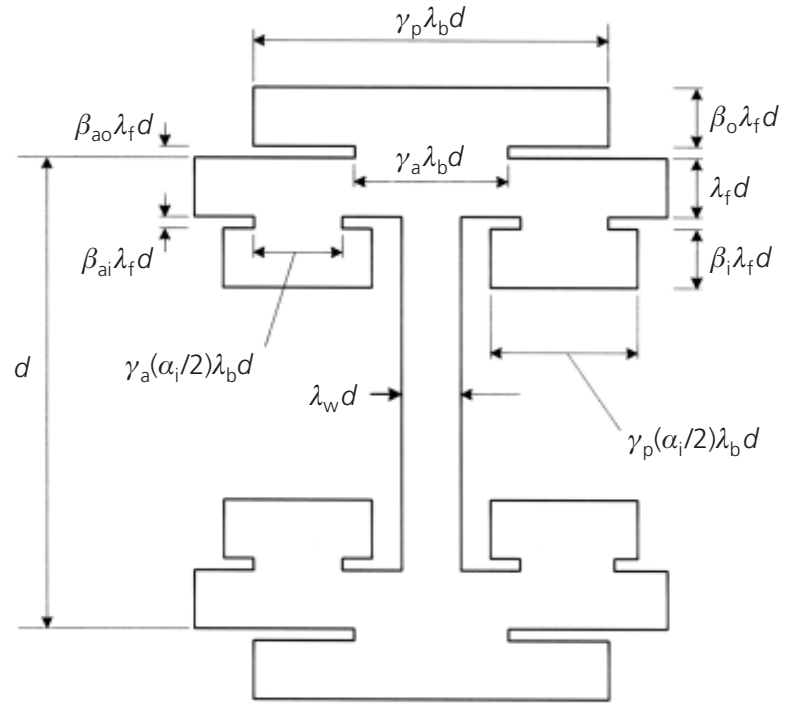

Figure 8. Transformed cross-section of a six-plate bonded splice joint (major-axis bending)

and $\gamma_{\mathrm{a}}$ and $\gamma_{\mathrm{p}}$ are the ratios of the adhesive elastic modulus and splice plate longitudinal elastic modulus to the beam's longitudinal elastic modulus, respectively.

From Figure 8 and a similar diagram for the transformed crosssection for minor-axis flexure, algebraic expressions may be derived for the evaluation of the factors $\phi_{\mathrm{A}}$ and $\phi_{\mathrm{I}}$. The expression for $\phi_{\mathrm{A}}$ is the same for both major and minor-axis flexure:

3.

$$
\phi_{\mathrm{A}}=2 \gamma_{\mathrm{p}} \lambda_{\mathrm{f}} \frac{\left\{\left(\beta_{\mathrm{o}}+\alpha_{\mathrm{i}} \beta_{\mathrm{i}}\right)+\left(\gamma_{\mathrm{a}} / \gamma_{\mathrm{p}}\right)\left(\beta_{\mathrm{ao}}+\alpha_{\mathrm{i}} \beta_{\mathrm{ai}}\right)\right\}}{\left\{1-\left[1-\left(\lambda_{\mathrm{w}} / \lambda_{\mathrm{b}}\right)\right]\left(1+2 \lambda_{\mathrm{f}}\right)\right\}}
$$

and the expression for $\phi_{\mathrm{I}}$ (for major-axis flexure only) is:

$$
\begin{aligned}
\phi_{\mathrm{I}}= & 2 \gamma_{\mathrm{p}} \lambda_{\mathrm{f}}^{3}\left\{\beta_{\mathrm{o}}^{3}\left[1+3\left(1+2 \frac{\beta_{\mathrm{ao}}}{\beta_{\mathrm{o}}}+\frac{1}{\beta_{\mathrm{o}} \lambda_{\mathrm{f}}}\right)^{2}\right]\right. \\
& +\alpha_{\mathrm{i}} \beta_{\mathrm{i}}^{3}\left[1+3\left(1+2 \frac{\beta_{\mathrm{ai}}}{\beta_{\mathrm{i}}}+\frac{2}{\beta_{\mathrm{i}}}-\frac{1}{\beta_{\mathrm{i}} \lambda_{\mathrm{f}}}\right)^{2}\right] \\
& +\frac{\gamma_{\mathrm{a}}}{\gamma_{\mathrm{p}}} \beta_{\mathrm{ao}}^{3}\left[1+3\left(1+\frac{1}{\beta_{\mathrm{ao}} \lambda_{\mathrm{f}}}\right)^{2}\right] \\
& \left.+\frac{\gamma_{\mathrm{a}}}{\gamma_{\mathrm{p}}} \alpha_{\mathrm{i}} \beta_{\mathrm{ai}}^{3}\left[1+3\left(1+\frac{2}{\beta_{\mathrm{ai}}}-\frac{1}{\beta_{\mathrm{ai}} \lambda_{\mathrm{f}}}\right)^{2}\right]\right\} \\
& \times\left[1-\left(1-\frac{\lambda_{\mathrm{w}}}{\lambda_{\mathrm{b}}}\right)\left(1-2 \lambda_{\mathrm{f}}\right)^{3}\right]^{-1}
\end{aligned}
$$




\section{Comparison of experimental and theoretical spliced beam deformations}

Equations 1-4 may be used to evaluate the centre deflection and end rotations for the serviceability test loads (i.e. the load corresponding to a mid-span deflection of $15 \mathrm{~mm}$ ) of each spliced beam with respect to its major and minor axis. These calculations were carried out using the manufacturer's minimum elastic modulus values for the beam and splice plate material and the corresponding modulus values determined from coupon tests (see Table 1) (note that the minimum value of the shear modulus was used in both sets of calculations).

The predicted deformations are compared with those determined from the major- and minor-axis flexure tests in Tables 3 and 4, respectively. In each row of each table the numbers are (from left to right) the serviceability test load, the splice length, the test

\begin{tabular}{|c|c|c|c|c|}
\hline $\begin{array}{l}\text { Load, } \\
W: \text { kN }\end{array}$ & $\begin{array}{l}\text { Splice length, } \\
\lambda L: \mathrm{mm}\end{array}$ & Test number* & $\begin{array}{c}\text { Centre deflection, } \\
\delta_{\mathrm{c}}^{S}: \mathrm{mm}\end{array}$ & $\begin{array}{l}\text { Average support rotation, } \\
\left(\left|\theta_{A}\right|+\left|\theta_{B}\right|\right) / 2 \text { : mrad }\end{array}$ \\
\hline 8 & 610 & $1 ; 2 ; 3$ & $15 \cdot 00$ & $\begin{array}{l}14 \cdot 31 ; 14 \cdot 25 ; 14 \cdot 38 \\
\text { Average (tests } 1-3 \text { ) }=14.31\end{array}$ \\
\hline 8 & 610 & Th. $1 ;$ Th. 2 & $16.98(13.2 \%) ; 13.95(-7.0 \%)$ & $17.91(25.2 \%) ; 14.59(2 \%)$ \\
\hline $7 \cdot 5$ & 410 & 1 & 15.00 & $14 \cdot 17$ \\
\hline $7 \cdot 6$ & 410 & $2 ; 3$ & $15 \cdot 00$ & $\begin{array}{l}14 \cdot 27 ; 14 \cdot 34 \\
\text { Average (tests } 2,3)=14 \cdot 31\end{array}$ \\
\hline $7 \cdot 6$ & 410 & Th. 1 ; Th. 2 & $17.76(18.4 \%) ; 14.59(-2.7 \%)$ & $18.31(28 \%) ; 14.92(4 \cdot 3 \%)$ \\
\hline $6 \cdot 6$ & 210 & 1 & $15 \cdot 00$ & $14 \cdot 16$ \\
\hline $6 \cdot 7$ & 210 & $2 ; 3$ & $15 \cdot 00$ & $\begin{array}{l}13 \cdot 82 ; 13 \cdot 76 \\
\text { Average (tests } 2,3)=13 \cdot 79\end{array}$ \\
\hline $6 \cdot 7$ & 210 & Th. 1 ; Th. 2 & $17 \cdot 34(15 \cdot 6 \%) ; 14.24(-5 \cdot 1 \%)$ & $17 \cdot 37(26 \%) ; 14 \cdot 16(2 \cdot 7 \%)$ \\
\hline
\end{tabular}

* Theoretical values Th. 1 and Th. 2 were calculated using the manufacturer's minimum and tension coupon elastic modulus values, respectively. The percentage values are [(Th. 1 or Th. 2$) /($ Test $)-1] \times 100$

Table 3. Comparison of theoretical and experimental centre deflections and average support rotations of pultruded GFRP beams with six-plate bonded splice joints at mid-span: major-axis flexure

\begin{tabular}{|c|c|c|c|c|}
\hline $\begin{array}{l}\text { Load, } \\
W: \text { kN }\end{array}$ & $\begin{array}{l}\text { Splice length, } \\
\lambda L: \mathrm{mm}\end{array}$ & Test number* & $\begin{array}{l}\text { Centre deflection, } \\
\qquad \delta_{c}^{S}: \mathrm{mm}\end{array}$ & $\begin{array}{l}\text { Average support rotation, } \\
\left(\left|\theta_{A}\right|+\left|\theta_{B}\right|\right) / 2 \text { : mrad }\end{array}$ \\
\hline $2 \cdot 8$ & 610 & $1 ; 2 ; 3$ & $15 \cdot 00$ & $\begin{array}{l}15 \cdot 81 ; 15 \cdot 81 ; 16 \cdot 08 \\
\text { Average (tests } 1-3)=15.90\end{array}$ \\
\hline $2 \cdot 8$ & 610 & Th. $1 ;$ Th. 2 & $17.67(17.8 \%) ; 14.43(-3.8 \%)$ & $19 \cdot 31(21 \cdot 4 \%) ; 15 \cdot 73(-1 \cdot 1 \%)$ \\
\hline $2 \cdot 4$ & 410 & $1 ; 2 ; 3$ & $15 \cdot 00$ & $\begin{array}{l}16 \cdot 41 ; 16 \cdot 21 ; 15 \cdot 48 \\
\text { Average (tests } 1-3)=16.03\end{array}$ \\
\hline $2 \cdot 4$ & 410 & Th. $1 ;$ Th. 2 & $16.86(12.4 \%) ; 13.78(-8.1 \%)$ & $17.93(11.9 \%) ; 14.61(-8.9 \%)$ \\
\hline $2 \cdot 1$ & 210 & $1 ; 2 ; 3$ & $15 \cdot 00$ & $\begin{array}{l}14 \cdot 73 ; 15 \cdot 01 ; 15 \cdot 26 \\
\text { Average (tests } 1-3)=15 \cdot 00\end{array}$ \\
\hline $2 \cdot 1$ & 210 & Th. 1; Th. 2 & $16 \cdot 52(10 \cdot 1 \%) ; 13 \cdot 49(-10 \cdot 1 \%)$ & $16.99(13.3 \%) ; 13.84(-7.7 \%)$ \\
\hline
\end{tabular}

* Theoretical values Th. 1 and Th. 2 were calculated using the manufacturer's minimum and tension coupon elastic modulus values, respectively. The percentage values are [(Th. 1 or Th. 2)/(Test) -1$] \times 100$

Table 4. Comparison of theoretical and experimental centre deflections and average support rotations of pultruded GFRP beams with six-plate bonded splice joints at mid-span: minor-axis flexure 
numbers, the centre deflection and the individual average and the average of the individual averages of the support rotations. In Table 3 there are two sets of values for the $210 \mathrm{~mm}$ and $410 \mathrm{~mm}$ splice lengths because the load corresponding to the deflection serviceability limit for test 1 was slightly less than that for tests 2 and 3. Likewise, in Tables 3 and 4 there are two sets of theoretical values (Th. 1 and Th. 2) for centre deflection, etc., calculated using the serviceability test load in Equations 1-4. The percentages, given in brackets after each theoretical deflection and average of average support rotations, are the differences between the predicted (calculated) and test values. In general, the predictions based on the manufacturer's elastic moduli tend to overestimate deflections by $10-18 \%$, whereas those based on coupon test moduli underestimate deflections by $3-10 \%$. On the other hand, predicted averages of average end rotations are overestimated by $12-28 \%$ using the manufacturer's moduli, whereas using coupon test moduli they are estimated to within $10 \%$. These observations suggest that deflections predicted using shear deformation beam theory and test coupon moduli are reasonably accurate. Hence they could be used for the serviceability limit state design of spliced beams.

\section{Parametric analyses of simply supported pultruded beams with mid-span splice joints}

The comparisons presented in Tables 3 and 4 demonstrate that Equation 1 may be used to predict the mid-span deflections of simply supported pultruded GFRP spliced beams loaded in threepoint flexure to within a few percent of the measured values. Therefore, Equation 1 may be used to investigate how the various splice joint parameters (e.g. adhesive thickness and modulus, splice plate thickness, etc.) affect the mid-span deflection. However, before describing and presenting the results of such parameter studies, it is helpful give further consideration to Equation 1. Clearly, it has two degenerate forms. The first form corresponds to the equation for the mid-span deflection $\delta_{\mathrm{c}}^{\mathrm{U}}$ of an unspliced beam and is obtained by setting $\lambda=0$. Hence, Equation 1 reduces to:

5. $\quad \delta_{\mathrm{c}}^{\mathrm{U}}=\frac{W L^{3}}{48 E I}(1+12 \alpha)$

The second degenerate form is obtained by setting $\lambda=1$ so that the mid-span deflection $\delta_{\mathrm{c}}^{\mathrm{F}}$ of a shear-deformable beam with splice plates extending over the entire span may be expressed as:

6.

$$
\delta_{\mathrm{c}}^{\mathrm{F}}=\frac{W L^{3}}{48 E I}\left\{\frac{1}{\left(1+\phi_{\mathrm{I}}\right)}+\frac{12 \alpha}{\left(1+\phi_{\mathrm{A}}\right)}\right\}
$$

Now the normalised mid-span deflection $\delta_{\mathrm{c}}^{\mathrm{N}}$ of a simply supported spliced beam in three-point flexure is obtained by dividing Equation 1 by Equation 5 and may be expressed as:

$$
\text { 7. } \delta_{\mathrm{c}}^{\mathrm{N}}=\frac{\delta_{\mathrm{c}}^{\mathrm{S}}}{\delta_{\mathrm{c}}^{\mathrm{U}}}=\frac{\begin{array}{c}
(1-\lambda)^{3}+\lambda\left[\left(3-3 \lambda+\lambda^{2}\right) /\left(1+\phi_{\mathrm{I}}\right)\right] \\
+12 \alpha\left\{(1-\lambda)+\left[\lambda /\left(1+\phi_{\mathrm{A}}\right)\right]\right\}
\end{array}}{(1+12 \alpha)}
$$

Again, there are two degenerate forms of Equation 7 corresponding to $\lambda=0$ and $\lambda=1$. In the former case, Equation 7 reduces to:

$$
\text { 8. } \delta_{\mathrm{c}}^{\mathrm{N}}=1
$$

and in the latter case it reduces to:

9. $\delta_{\mathrm{c}}^{\mathrm{N}}=\frac{\left[1 /\left(1+\phi_{\mathrm{I}}\right)\right]+\left[12 \alpha /\left(1+\phi_{\mathrm{A}}\right)\right]}{(1+12 \alpha)}$

\subsection{Parameter study 1: Effect of splice length and beam span}

In this parameter study, the effect of the length of the six-plate splice joints on the mid-span deflection was investigated for several beam spans. The beams and splice joints had the same cross-section geometry and material properties as the experimental beams and the adhesive thickness was assumed to be zero. Three spans were selected, namely $3 \mathrm{~m}$ (the same as the experimental beams), $1.5 \mathrm{~m}$ and $0.75 \mathrm{~m}$. The latter span is too short to be of practical significance but was retained in the study in order to highlight the effects of shear deformation on the mid-span deflection.

The results of the parameter study are presented in Figure 9, which shows a plot of the normalised mid-span deflection $\delta_{c}^{\mathrm{N}}$

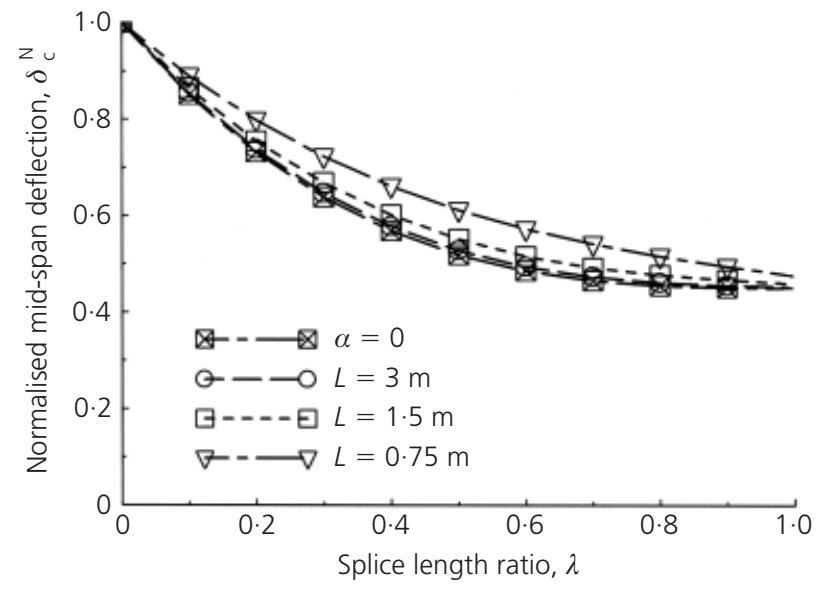

Figure 9. Normalised mid-span deflection versus splice length ratio for shear-rigid and shear-deformable pultruded GFRP $152 \times 152 \times 6.4 \mathrm{~mm}$ WF beams with pultruded GFRP $6.4 \mathrm{~mm}$ thick six-plate splice joints and different spans 
versus the splice length ratio $\lambda$. As expected, all of the curves show a steady reduction in the normalised mid-span deflection as the splice length ratio increases. The curve corresponding to $\alpha=0$ represents the classical shear-rigid beam response and is independent of the span $L$. However, for shear-deformable beams, the normalised mid-span deflection depends on the span because the shear flexibility parameter $\alpha$ is inversely proportional to $L^{2}$. Consequently, as the span $L$ decreases, so $\alpha$ increases and the contribution of shear deformation to the real mid-span deflection also increases. Nevertheless, as shown in Figure 9, the normalised deflection $\delta_{c}^{N}$ reduces as the span increases because the $\alpha$ term in the denominator of Equation 7 has a greater effect than the corresponding term in the numerator. Nevertheless, for span to depth ratios in the range of $10-25$, the effect of shear deformation is small.

Equation 2, which may be used to estimate the end rotations of spliced beams, is independent of the shear flexibility parameter $\alpha$. The term in square brackets on the right-hand side of Equation 2 may be regarded as a rotation reduction factor $\phi_{\theta}$. It has two degenerate forms - one for the rotation reduction factor $\phi_{\theta}^{\mathrm{U}}$ of an unspliced beam $(\lambda=0)$ and the other for the rotation reduction factor $\phi_{\theta}^{\mathrm{F}}$ of a beam with the splice extending over the whole span $(\lambda=1)$. In the former case, the rotation reduction factor reduces to:

10. $\phi_{\theta}^{\mathrm{U}}=1$

and in the latter case it reduces to:

11. $\phi_{\theta}^{\mathrm{F}}=\frac{1}{\left(1+\phi_{\mathrm{I}}\right)}$

A plot of the support rotation reduction factor $\phi_{\theta}$ versus splice length ratio $\lambda$ corresponding to the geometry and material properties of the beam and splice plates of the experimental beams is shown in Figure 10. It is evident that as the splice length ratio $\lambda$ increases, $\phi_{\theta}$ reduces gradually from unity to 0.45 as the beam changes from being unspliced to one in which the splice extends over the entire span.

Whilst the normalised deflection versus splice length ratio plot shown in Figure 9 may be helpful for trial-and-error design of spliced beams, it would be even more helpful for a designer to have some means of determining what the optimum and limiting splice lengths are for a particular splice joint configuration. It is possible to determine these lengths by means of graphs of the normalised reduction in mid-span deflection $\delta_{c}^{R}$, defined as:

12. $\delta_{\mathrm{c}}^{\mathrm{R}}=1-\delta_{\mathrm{c}}^{\mathrm{N}}$

versus the splice length ratio $\lambda$ for different beam spans and

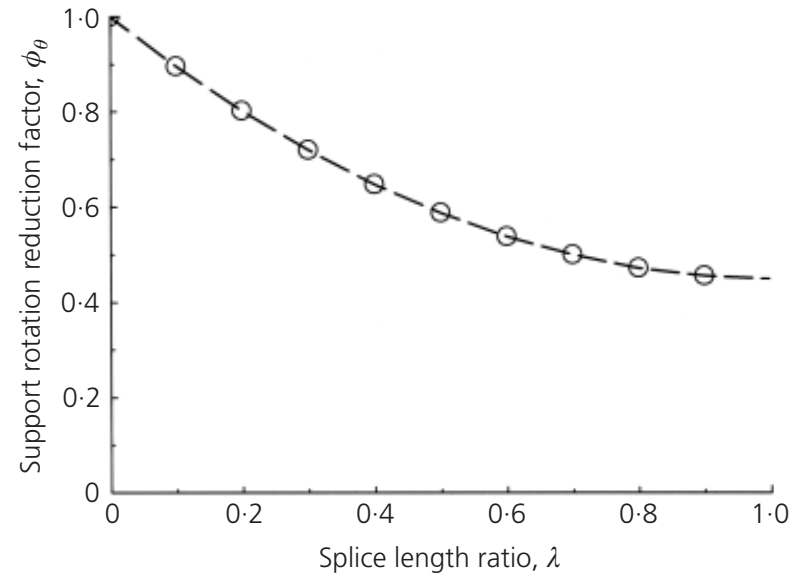

Figure 10. Support rotation reduction factor versus splice length ratio for pultruded GFRP $152 \times 152 \times 6.4 \mathrm{~mm}$ WF beams with pultruded GFRP $6.4 \mathrm{~mm}$ thick six-plate splice joints

superimposing on them the straight line graph of $\lambda$ versus $\lambda$. Such graphs have been produced using the normalised deflection data of Figure 9 and are shown in Figure 11. It is evident that the straight line representing $\lambda$ versus $\lambda$ intersects each of the reduction in mid-span deflection $\delta_{\mathrm{c}}^{\mathrm{R}}$ curves at unique values of $\lambda$. These values are the limiting splice length $\lambda_{\text {lim }}$ ratios for each span because the difference between the slopes of the $\lambda$ and $\delta_{c}^{R}$ curves begins to increase dramatically as $\lambda$ increases beyond the values at the intersection points. For the spliced beam spans of $0.75,1.5$ and $3 \mathrm{~m}$, the limiting splice length ratios $\lambda_{\lim }$ are $0.2383,0.4045$ and 0.4501 , respectively. However, the optimum splice length ratio $\lambda_{\text {opt }}$ corresponds to the value of $\lambda$ at which the slopes of the $\delta_{c}^{R}$ and $\lambda$ curves are equal. Again, for the spliced beam spans of $0.75,1.5$ and $3 \mathrm{~m}$, the optimum splice length ratios $\lambda_{\text {opt }}$ are $0 \cdot 1165,0 \cdot 1937$ and $0 \cdot 2143$, respectively.

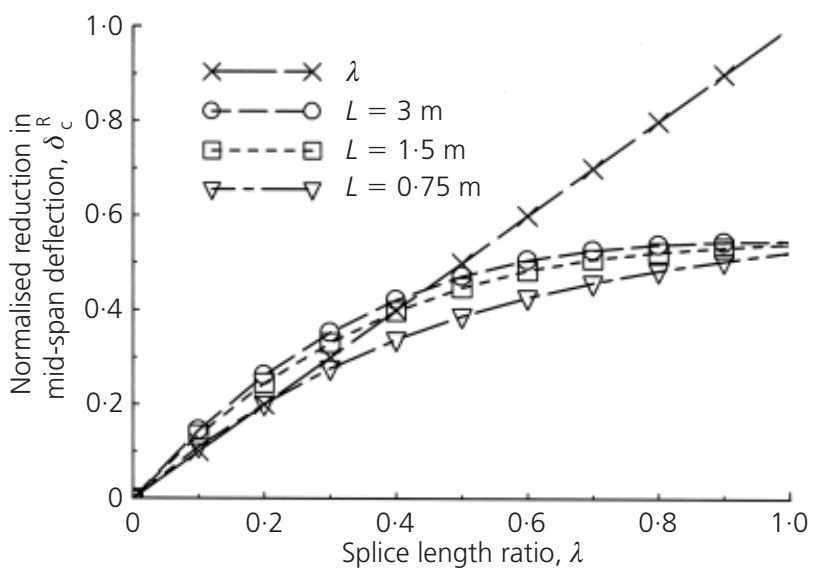

Figure 11. Normalised reduction in mid-span deflection versus splice length ratio for pultruded GFRP $152 \times 152 \times 6.4 \mathrm{~mm}$ WF beams with pultruded GFRP $6.4 \mathrm{~mm}$ thick six-plate splice joints and different spans 
It can readily be shown that the limiting and optimum values of the splice length ratios may be determined as the smaller (corresponding to $\lambda \leqslant 1$ ) of the two roots of the quadratic equation:

13. $a \lambda^{2}+b \lambda+c=0$

To determine the limiting splice length ratio $\lambda_{\text {lim }}$, the coefficients in Equation 13 are:

$$
\text { 14a. } a=\frac{\phi_{\mathrm{I}}}{\left(1+\phi_{\mathrm{I}}\right)}
$$

14b. $b=-\frac{3 \phi_{\mathrm{I}}}{\left(1+\phi_{\mathrm{I}}\right)}$

14c. $c=\left[2-\frac{3}{\left(1+\phi_{\mathrm{I}}\right)}+\frac{12 \alpha}{\left(1+\phi_{\mathrm{A}}\right)}\right]$

Similarly, to determine the optimum splice length ratio $\lambda_{\text {opt }}$, the coefficients in Equation 13 are:

15a. $a=\frac{3 \phi_{\mathrm{I}}}{\left(1+\phi_{\mathrm{I}}\right)}$

15b. $b=-\frac{6 \phi_{\mathrm{I}}}{\left(1+\phi_{\mathrm{I}}\right)}$

15c. $c=-\left[\frac{\left(1-2 \phi_{\mathrm{I}}\right)}{\left(1+\phi_{\mathrm{I}}\right)}+\frac{12 \alpha}{\left(1+\phi_{\mathrm{A}}\right)}\right]$

\subsection{Parameter study 2: Effect of adhesive thickness and} elastic modulus

In order to quantify the effect of the adhesive's thickness, $t_{\mathrm{a}}$, and elastic modulus, $E_{\mathrm{a}}$, on the normalised mid-span deflection, it was again decided to use the beam and splice joint cross-section geometries and $3 \mathrm{~m}$ span of the experimental beams. The additional cross-sectional area, $\phi_{\mathrm{A}}$, and additional second moment of area, $\phi_{\mathrm{I}}$, of the six-plate splice joint cross-section were evaluated using Equations 3 and 4, respectively. For the case of zero adhesive thickness (which was assumed in the calculations to predict the mid-span deflections of the experimental beams) the values of $\phi_{\mathrm{A}}$ and $\phi_{\mathrm{I}}$ were 0.9374 and 1.2202 , respectively.
In the parameter study, five non-zero adhesive thicknesses $t_{\mathrm{a}}$ were assumed $(0.5,1.0,1.5,2.0$ and $3.0 \mathrm{~mm})$. These thicknesses were considered sufficient to span the likely practical range. Three values of the adhesive elastic modulus, $E_{\mathrm{a}}$, were also selected (3, 6 and $10 \mathrm{kN} / \mathrm{mm}^{2}$ ). Again, these were considered sufficient to span the likely practical range of moduli. It should be appreciated that the present simple analysis does not allow the shear modulus of the adhesive to be included in the analysis.

Values of $\phi_{\mathrm{A}}$ and $\phi_{\mathrm{I}}$ were computed for each adhesive thickness and elastic modulus. Normalised values of additional crosssectional area, $\phi_{\mathrm{A}}^{\mathrm{N}}$, and additional second moment of area, $\phi_{\mathrm{I}}^{\mathrm{N}}$, were then determined by dividing the $\phi_{\mathrm{A}}$ and $\phi_{\mathrm{I}}$ values by the corresponding values for the zero adhesive thickness. Plots of normalised additional cross-sectional area, $\phi_{\mathrm{A}}^{\mathrm{N}}$, and normalised additional second moment of area, $\phi_{\mathrm{I}}^{\mathrm{N}}$, versus adhesive thickness for three values of adhesive elastic modulus $E_{\mathrm{a}}$ are shown in Figures 12 and 13, respectively. From these figures it is evident that both $\phi_{\mathrm{A}}^{\mathrm{N}}$ and $\phi_{\mathrm{I}}^{\mathrm{N}}$ increase linearly with increasing adhesive thickness and increasing adhesive elastic modulus. Moreover, the maximum values of $\phi_{\mathrm{A}}^{\mathrm{N}}$ and $\phi_{\mathrm{I}}^{\mathrm{N}}$ (corresponding to the maximum values of adhesive thickness and modulus) are 31 and $32 \%$ higher respectively than their corresponding zero adhesive thickness values. Although these percentage increases are substantial, when the $\phi_{\mathrm{A}}^{\mathrm{N}}$ and $\phi_{\mathrm{I}}^{\mathrm{N}}$ values are used in Equation 7 to determine the normalised mid-span deflection, $\delta_{\mathrm{c}}^{\mathrm{N}}$, it is clear, as shown in Figure 14, that they have little effect on the normalised mid-span deflections. For example, the difference between the normalised mid-span deflection for zero adhesive thickness and that for a $3 \mathrm{~mm}$ thick adhesive with a $10 \mathrm{kN} / \mathrm{mm}^{2}$ elastic modulus is about $3 \%$ when the splice length ratio $\lambda=0 \cdot 4$. Hence, it would appear that neither the adhesive thickness nor its elastic modulus have much impact on the normalised mid-span deflection of pultruded GFRP beams with six-plate splice joints.

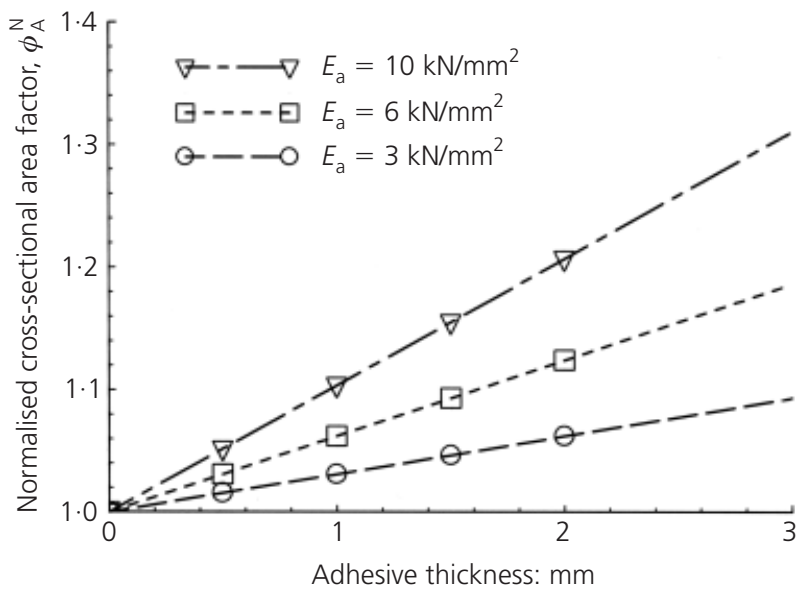

Figure 12. Normalised cross-sectional area factor versus adhesive thickness for different adhesive elastic moduli for $3 \mathrm{~m}$ span pultruded GFRP $152 \times 152 \times 6.4 \mathrm{~mm}$ WF beams with pultruded GFRP $6.4 \mathrm{~mm}$ thick six-plate splice joints 


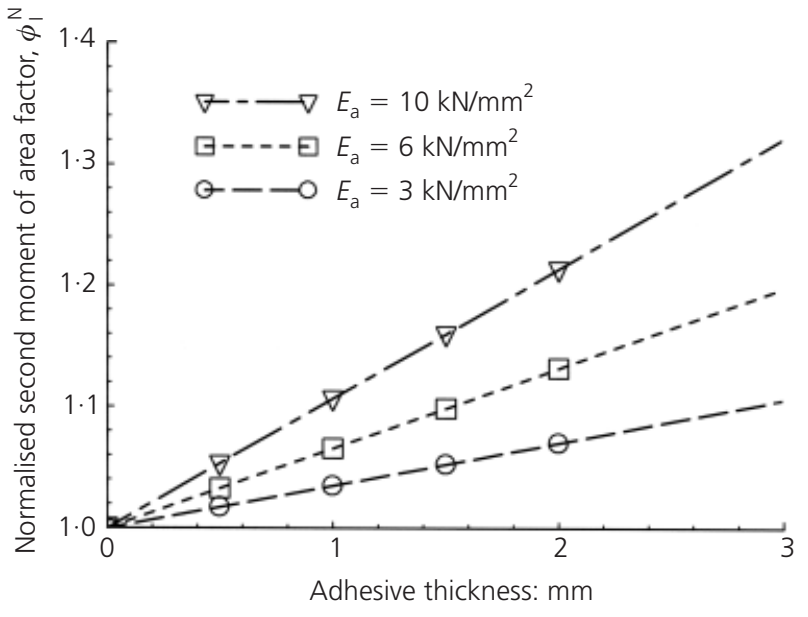

Figure 13. Normalised second moment of area factor versus adhesive thickness for different adhesive elastic moduli for $3 \mathrm{~m}$ span pultruded GFRP $152 \times 152 \times 6.4 \mathrm{~mm}$ WF beams with pultruded GFRP $6.4 \mathrm{~mm}$ thick six-plate splice joints

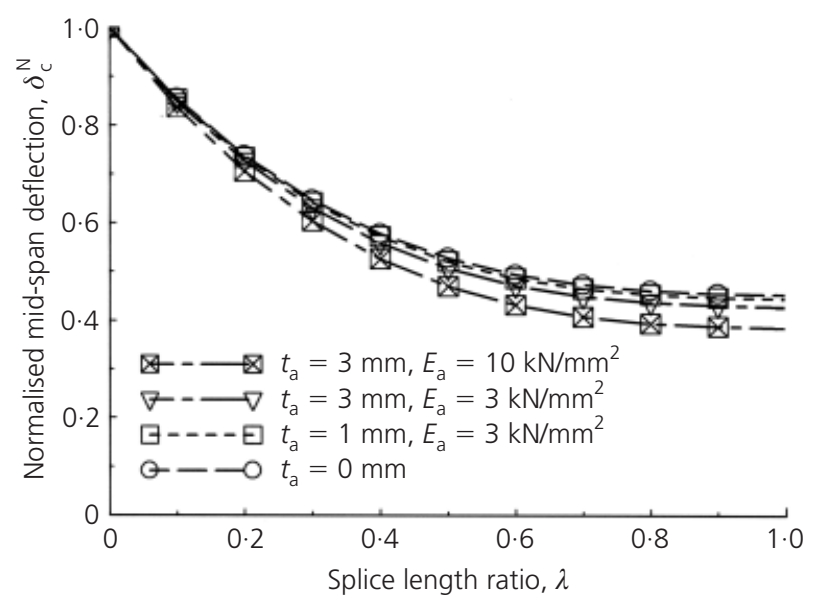

Figure 14. Normalised mid-span deflection versus splice length ratio for different adhesive thicknesses and elastic moduli for $3 \mathrm{~m}$ span pultruded GFRP $152 \times 152 \times 6.4 \mathrm{~mm}$ WF beams with pultruded GFRP $6.4 \mathrm{~mm}$ thick six-plate splice joints

\subsection{Parameter study 3: Effect of splice plate thickness and layout}

The effects of different pultruded GFRP splice plate thicknesses, $t_{\mathrm{p}}$, on the normalised mid-span deflections, $\delta_{\mathrm{c}}^{\mathrm{N}}$, were investigated first. The cross-section geometry, elastic moduli and span of the pultruded GFRP WF beam were the same as those of the experimental beams. Moreover, the thicknesses of the inner and outer splice plates (assumed equal) corresponded to those available off-the-shelf. Thus, the nominal plate thicknesses, $t_{\mathrm{p}}$, ranged from 3.2 to $25.4 \mathrm{~mm}$ (Strongwell, 1989). Even though the larger thicknesses are most probably too large to be used to splice a beam with $6.4 \mathrm{~mm}$ thick flanges, they were retained in the study for the sake of completeness. Moreover, in the light of parameter study 2, the values of $\phi_{\mathrm{A}}$ and $\phi_{\mathrm{I}}$ used in Equation 7 were those for zero adhesive thickness.

Figure 15 shows the normalised mid-span deflection, $\delta_{c}^{N}$, plotted against the splice length ratio, $\lambda$. It is self-evident $\delta_{\mathrm{c}}^{\mathrm{N}}$ reduces significantly as the thickness of the GFRP splice plates increases. Moreover, it appears that increasing the splice plate thickness $t_{\mathrm{p}}$ from $3.2 \mathrm{~mm}$ to $6.4 \mathrm{~mm}$ and also from $6.4 \mathrm{~mm}$ to $12.7 \mathrm{~mm}$ produces significant reductions in $\delta_{\mathrm{c}}^{\mathrm{N}}$ for near-optimal splice length ratios (i.e. $\lambda=0 \cdot 2$ ). On the other hand, splice plate thicknesses greater than $12.7 \mathrm{~mm}$ appear to show diminishing returns in reducing the normalised mid-span deflection.

In the second part of this parameter study, the layouts, thicknesses and elastic moduli of the splice plates were varied in order to assess the effects of changing them on the normalised mid-span deflection for the practical range of splice length ratios.

Figure 16 compares the normalised mid-span deflections, $\delta_{\mathrm{c}}^{\mathrm{N}}$, of a pultruded GFRP spliced beam with three pultruded GFRP splice plate layouts for splice length ratios, $\lambda$, ranging from $0 \cdot 1$ to $0 \cdot 4$. The splice plate layouts were: (a) two $6.4 \mathrm{~mm}$ thick plates bonded to the outer surfaces of the flanges; (b) two $6.4 \mathrm{~mm}$ thick plates bonded to the outer surfaces of the flanges and four $3.2 \mathrm{~mm}$ thick plates bonded to the inner surfaces of the flanges; and (c) two $6.4 \mathrm{~mm}$ thick plates bonded to the outer surfaces of the flanges and four $6.4 \mathrm{~mm}$ thick plates bonded to the inner surfaces of the flanges.

As expected, splice plate layout (c) results in the smallest and splice plate layout (a) in the largest normalised mid-span deflection for all splice length ratios. The differences in mid-span deflection between the three splice plate layouts appear to

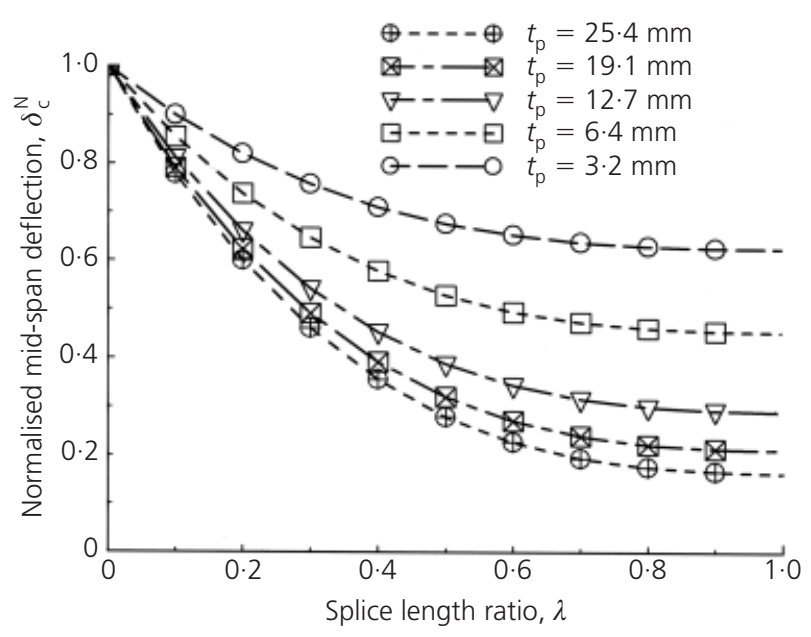

Figure 15. Normalised mid-span deflection versus splice length ratio for $3 \mathrm{~m}$ span pultruded GFRP $152 \times 152 \times 6.4 \mathrm{~mm} \mathrm{WF}$ beams with pultruded GFRP six-plate splice joints of different plate thicknesses 


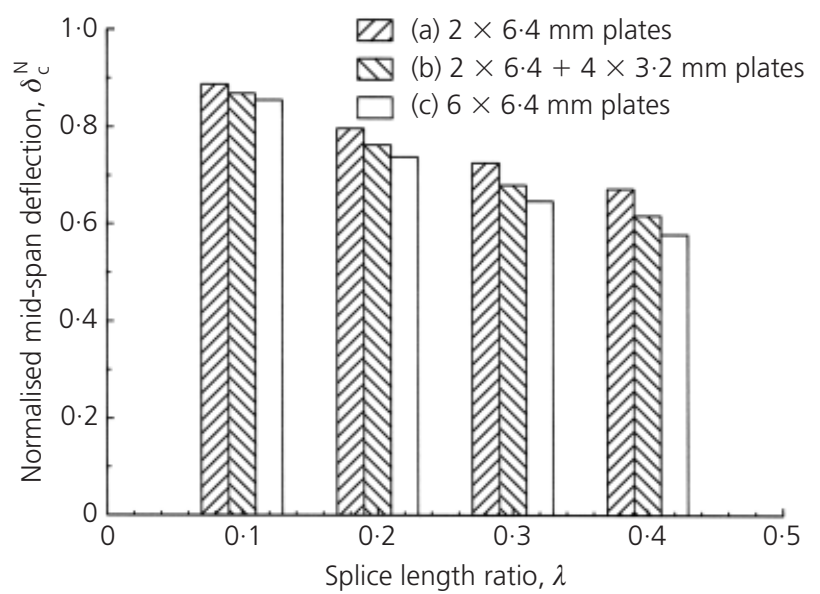

Figure 16. Normalised mid-span deflection for selected splice length ratios of $3 \mathrm{~m}$ span pultruded GFRP $152 \times 152 \times 6.4 \mathrm{~mm}$ WF beams with splice plate layouts (a), (b) and (c) based on $6.4 \mathrm{~mm}$ and $3.2 \mathrm{~mm}$ thick GFRP plates

increase as the splice length ratio increases. A corresponding set of results for the same three splice plate layouts but based on $12.7 \mathrm{~mm}$ and $6.4 \mathrm{~mm}$ thick pultruded GFRP plates is shown in Figure 17. The results trends are the same but, of course, the normalised mid-span deflections are smaller.

In the final part of the study, pultruded GFRP beams with the same three splice plate layouts were analysed based on $2 \mathrm{~mm}$ and $1 \mathrm{~mm}$ thick pultruded unidirectional CFRP plates with a longitudinal elastic modulus of $125 \mathrm{kN} / \mathrm{mm}^{2}$. The normalised midspan deflections, $\delta_{\mathrm{c}}^{\mathrm{N}}$, for splice length ratios, $\lambda$, ranging from $0 \cdot 1$ to 0.4 are shown in Figure 18. Again, the results trends are the same as in Figures 16 and 17. However, comparing the corre-

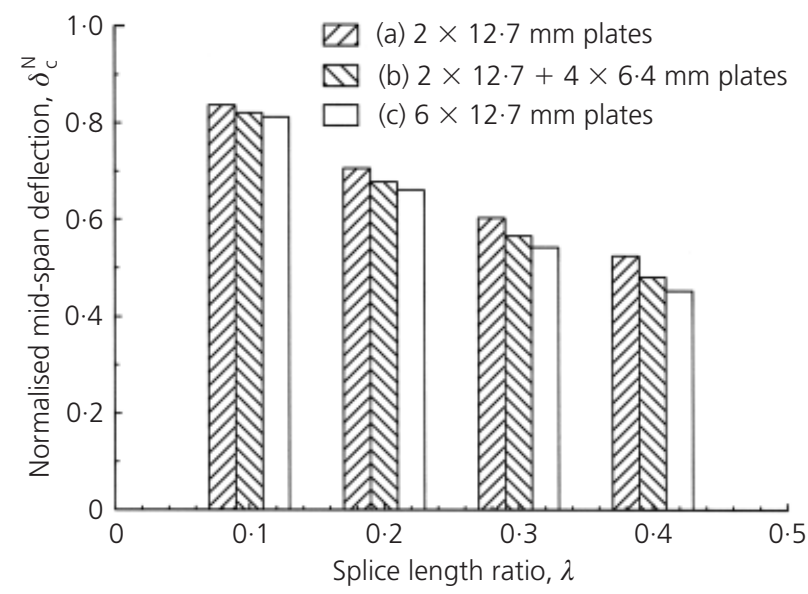

Figure 17. Normalised mid-span deflection for selected splice length ratios of $3 \mathrm{~m}$ span pultruded GFRP $152 \times 152 \times 6.4 \mathrm{~mm}$ WF beams with splice plate layouts (a), (b) and (c) based on $12.7 \mathrm{~mm}$ and $6.4 \mathrm{~mm}$ thick GFRP plates

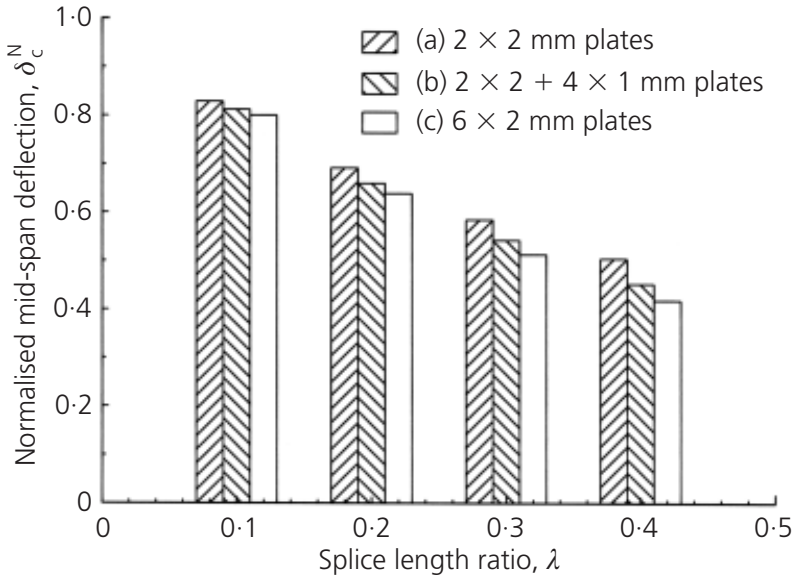

Figure 18. Normalised mid-span deflection for selected splice length ratios of $3 \mathrm{~m}$ span pultruded GFRP $152 \times 152 \times 6.4 \mathrm{~mm}$ WF beams with splice plate layouts (a), (b) and (c) based on $2 \mathrm{~mm}$ and $1 \mathrm{~mm}$ pultruded unidirectional CFRP plates

sponding $\delta_{\mathrm{c}}^{\mathrm{N}}$ values in Figures 17 and 18, it is evident that the splice plate layouts based on $2 \mathrm{~mm}$ and $1 \mathrm{~mm}$ thick CFRP plates reduce the mid-span deflections slightly more than splice plate layouts based on $12.7 \mathrm{~mm}$ and $6.4 \mathrm{~mm}$ thick GFRP plates.

\section{Concluding remarks}

(a) Elastic moduli derived from tension tests on coupons cut out of pultruded GFRP WF beam and plate profiles were compared with and shown to be significantly larger than the design values given in the manufacturer's design manual.

(b) The procedures adopted to fabricate three pultruded GFRP beams each with a six-plate bonded splice joint of different length at mid-span were described.

(c) The instrumentation used to record deflections, rotations and strains during displacement-controlled serviceability limit state three-point flexure tests on the spliced beams was described.

(d) Mid-span deflections and support rotations were compared with analytical predictions based on a simple sheardeformable spliced beam theory. It was shown that deflections are predicted to within $10 \%$, provided that elastic moduli based on coupon tests are used rather than the manufacturer's design values. End rotations are predicted less accurately with the theory.

(e) The simple spliced beam theory was used to conduct three parameter studies. In the first study, the effect of splice length ratio on normalised mid-span deflection was quantified. Optimum and limiting splice length ratios were defined and formulae presented for their evaluation. The second parameter study showed that adhesive thickness and elastic modulus have a minimal influence on normalised mid-span deflection for practical splice length ratios. The third study investigated the effect of three splice plate layouts (based on three GFRP plate thicknesses and two unidirectional CFRP 
plate thicknesses) on normalised mid-span deflection. It was shown that thin CFRP splice plate layouts reduce the normalised mid-span deflections slightly more than the thicker GFRP splice plate layouts.

\section{Acknowledgements}

The author wishes to acknowledge the contribution of Ms S. Breton, a French summer internee, who carried out the test work under the author's direction as part of her project work. The author also wishes to thank the Engineering Department's technical staff for help with the test work.

\section{REFERENCES}

Case J and Chilver AH (1959) Strength of Materials. Edward Arnold, London.

Clarke JL (ed.) (1996) Structural Design of Polymer Composites: EUROCOMP Design Code and Handbook. E \& FN Spon, London.

Keller T and Vallée T (2005a) Adhesively bonded lap joints from pultruded GFRP profiles. Part I: Stress-strain analysis and failure modes. Composites Part B: Engineering 36(4): $331-$ 340.

Keller T and Vallée T (2005b) Adhesively bonded lap joints from pultruded GFRP profiles. Part II: Joint strength prediction. Composites Part B: Engineering, 36, No. 4, 341-350. Mottram JT and Turvey GJ (2003) Physical test data for the appraisal of design procedures for bolted joints in pultruded FRP structural shapes and systems. Progress in Structural Engineering and Materials 5(4): 195-222.

Strongwell (1989) EXTREN ${ }^{\circledR}$ Fiberglass Structural Shapes: Design Manual. Strongwell, Bristol, VA.

Turvey GJ (2000) Bolted connections in PFRP structures. Progress in Structural Engineering and Materials 2(2): 146156.

Turvey GJ (2008) Bending of tip-loaded CFRP stiffened pultruded GRP cantilevers. Proceedings of 13th European Conference on Composite Materials (ECCM 13), Stockholm. CD Rom.

Turvey GJ and Cooper C (2004) Review of tests on bolted joints between pultruded GRP profiles. Proceedings of the Institution of Civil Engineers, Structures and Buildings 157(3): 211-233.

Vallée T, Correia JR and Keller T (2006a) Probabilistic strength prediction for double lap joints composed of pultruded GFRP profiles. Part I: Experimental and numerical investigations. Composites Science and Technology 66(13): 1903-1914.

Vallée T, Correia JR and Keller T (2006b) Probabilistic strength prediction for double lap joints composed of pultruded GFRP profiles. Part II: Strength prediction. Composites Science and Technology 66(13): 1915-1930.

Zhang Y and Keller T (2008) Progressive failure process of adhesively bonded joints composed of pultruded GFRP. Composites Science and Technology 68(2): 461-470.

\section{WHAT DO YOU THINK?}

To discuss this paper, please email up to 500 words to the editor at journals@ice.org.uk. Your contribution will be forwarded to the author(s) for a reply and, if considered appropriate by the editorial panel, will be published as a discussion in a future issue of the journal.

Proceedings journals rely entirely on contributions sent in by civil engineering professionals, academics and students. Papers should be $2000-5000$ words long (briefing papers should be 1000-2000 words long), with adequate illustrations and references. You can submit your paper online via www.icevirtuallibrary.com/content/journals, where you will also find detailed author guidelines. 